\title{
To Determine the Incidence and Risk Factors Associated with Placenta Previa in a Tertiary Care Hospital of Pakistan
}

\author{
Sadia Asghar, ", Samra Asghar Cheema², Nafeesa Naz ${ }^{3}$ \\ ${ }^{1}$ Department of Obstetrics and Gynecology, Naizi Medical College, Sargodha, Pakistan \\ ${ }^{2}$ Department of Obstetrics and Gynecology, Sir Ganga Ram Hospital, Lahore, Pakistan \\ ${ }^{3}$ Department of Obstetrics and Gynecology, Allied Hospital, Faisalabad, Pakistan
}

Email address:

azanayan36@gmail.com (S. Asghar),smrcheema@gmail.com (S. A. Cheema), drnafeesanaaz@gmail.com (N. Naz)

${ }^{*}$ Corresponding author

\section{To cite this article:}

Sadia Asghar, Samra Asghar Cheema, Nafeesa Naz. To Determine the Incidence and Risk Factors Associated with Placenta Previa in a Tertiary Care Hospital of Pakistan. Journal of Gynecology and Obstetrics. Vol. 8, No. 3, 2020, pp. 67-70. doi: 10.11648/j.jgo.20200803.14

Received: March 9, 2020; Accepted: April 21, 2020; Published: May 28, 2020

\begin{abstract}
Placenta previa is the condition of pregnancy in which placenta implants in lower uterine segment, partially or completely covering the internal os. This condition may associate with many risk factors. Because with placenta previa pregnancy becomes high risk and fetomaternal morbidities and mortalities are also increased. By knowing the risk factors which are the main causative factors for placenta previa fetomaternal outcome can be optimized The purpose of this study is to find the incidence of placenta previa, and also determine the risk factors for placenta previa. This is descriptive prospective study. This study was done in tertiary care hospital of Pakistan. In this study total deliveries were 5381, total patient with previa were found $325(6.03 \%)$. The risk factors of placenta previa are age more than 35 years $(28.92 \%)$, smoking $(20.16 \%)$, multiparity (44\%), uterine scar $(60.30 \%)$, previous evacuation and curettage $(24.30 \%)$. According to age distribution to mostly patients about 135 out of 325 were found between age group of 36-40 years with percentage of $41.23 \%$. Distribution of patients accrding to gestational age mostly found between age 33-35 weeks with percentage of 54.76 percent amd according to gravidity mostly found between G5-G7 with percentage of 42.46 percent. Aim of the study is to find out the risk factors associated with placenta previa and also determine the incidence of placenta previa in tertiary care hospital of Pakistan.
\end{abstract}

Keywords: Fetomaternal, Morbidities, Mortalities

\section{Introduction}

Placenta previa occurs with an incidence of $0.3-0.5 \%$. It is defined by implantation of placenta in lower uterine segment, partially or completely covering the internal os [1]. It is an obstetric complication [2]. The estimated global prevalence of placenta previa is 5.2 per 1000 pregnant women, although there is significant variation where by the prevalence was highest among the Asian population and lower in Sub Saharan Africa studies [3]. Obstetric hemorrhage is a leading cause of fetomaternal morbidity and mortality [4].

Transabdominal and transvaginal ultrasound are complementary diagnostic techniques and should be used as needed. Transvaginal ultrasound is safe for patients with placenta previa and allows a more complete examination of the lower uterine segment [5]. The use of Doppler imagining does not significantly improve the diagnostics sensitivity compared with that achieved by gray scale ultrasonography alone [6].

Such abnormal placentation has been observed and show relationship with previous cesarean section [7, 8]. Other risk factors are uterine surgeries, such as myomectomy or curettage, advanced maternal age, multiparity and smoking $[7,9,10]$. Uterine scar is major risk factor for placenta previa and its complication like accrete, increta [11].

The prime factors responsible for neonatal morbidity and mortality in case of placenta previa is prematurity. Neonatal and maternal mortality is mainly due to birth asphyxia, prematurity with $24 \%$ needing NICU admission [12]. Pregnant women with placenta previa are carrying high risk pregnancy. This may have adverse fetomaternal outcome. fetomaternal morbidity, mortality is associated with this condition $[13,14]$. 


\section{Subject and Methods}

Study was conducted at department of Obstetrics and gynecology department of Ganga Ram hospital (Tertiary Care Hospital Pakistan) for 6 Months for period of June 2018 to December 2018. Total deliveries were 12,850. 325 Pregnant women included in the study were those with age of 20 - 40 years, primigravida to gravida 4 having single pregnancy on ultrasound with gestational age $\geq 28$ weeks on ultrasound and diagnosed cases of placenta previa major degree on ultrasound. Pregnant women having bleeding disorders (on investigations: decreased platelets count, deranged coagulation profile), Placental abruption (on ultrasound) were excluded. Informed consent was taken from the patient and data was kept anonymous for privacy.

325 pregnant women with placenta previa who presented in emergency as well as out patient department of Obstetrics and Gynecology department of Ganga Ram hospital and who fulfilled the above criteria were considered and explained the details of the study. Written informed consent was taken regarding personal information for the purpose of study. All the patients were followed till delivery.

Data was entered and analyzed by SPSS version 22 computer based software programme. Mean and Standard deviation were calculated for age, gestational age, duration of marriage, parity. Percentages of pregnant women with placenta previa with these risk factors like previous uterine scar, previous evacuation and curettage, smoking, multiparity, age more than 35 years were noted with $95 \%$ confidence level and $10 \%$ margin of errors.

\section{Result}

Distribution of cases by age shows, patients were between 20 - 40 years. Segregation of patients according to age were as $20-25$ years $47(14.4 \%), 26-30$ years $79(24.30 \%), 31-35$ years $65(20 \%)$ and 36-40 years $134(41.23 \%)$ (Table 1). Distribution of cases by gestational age shows, patient's gestational age between 28-32 weeks. 63 (19.38\%), 3335weeks $178(54.76 \%)$ and 36-40 weeks were 84 (25.84\%) patients (Table 2).

According to gravidity G2-G4 are 79 (24.30\%), G5-G7 are $139(42.46 \%)$ and $>$ G7 are 107 (32.9\%) (Table 3).

The risk factors with percentages are age more than 35 years $(28.92 \%)$, smoking (20.16\%), multiparity (44\%), uterine scar $(60.30 \%)$, previous evacuation and curettage $(24.30 \%)$ Table 4 Incidences of placenta previa was found $6.03 \%$ (Table 5).

Aim of the study is to find out the risk factors which are the major causative factors associated with placenta previa and also determine the incidence of placenta previa. Most studies reported association between previous cesarean section and placenta previa. Increased risk of placenta previa among multi gravid, may be explained by degenerative changes to uterine vascular which cause implantation on lower segment.

Table 1. Age of Pregnant Women With Placenta Previa.

\begin{tabular}{llll}
\hline Sr. No. & AGE OF PATIENT & NUMBER OF PATIENT & PERCENTAGE (\%) \\
\hline 1 & $20-25$ & 47 & 14.46 \\
2 & $26-30$ & 79 & 24.30 \\
3 & $31-35$ & 35 & 20 \\
4 & $36-40$ & 134 & 41.23 \\
\hline
\end{tabular}

Table 2. Gestational Age of Pregnant Women With Placenta Previa.

\begin{tabular}{llll}
\hline Sr. No. & GESTATIONAL AGE WEEKS & NUMBER OF PATIENTS (325) & PERCENTAGE (\%) \\
\hline 1 & $28-32$ & 63 & 19.38 \\
2 & $33-35$ & 178 & 54.76 \\
3 & $36-40$ & 84 & 25.84 \\
\hline
\end{tabular}

Table 3. Gravidity And Parity of Pregnant Women with Placenta Previa.

\begin{tabular}{llll}
\hline Sr. No. & GRAVIDITY OF PATIENT & NUMBER OF PATIENT (325) & PERCENTAGE (\%) \\
\hline 1 & G2-G4 & 79 & 32.36 \\
2 & G5-G7 & 139 & 52.65 \\
3 & $>$ G7 & 107 & 14.9 \\
\hline
\end{tabular}

Table 4. Percentage of The Risk Factors.

\begin{tabular}{llll}
\hline Sr. No & RISK FACTORS & NUMBER OF PATIENTS & PERCENTAGE \\
\hline 1 & Total Placenta Previa & 325 & $2.59 \%$ \\
2 & Age $>35$ & 94 & $28.92 \%$ \\
3 & Smoking & 67 & $20.61 \%$ \\
4 & Multiparity & 143 & $44 \%$ \\
5 & Scared uterus & 196 & $60.30 \%$ \\
6 & Previous evacuation and curettage & 79 & $24.32 \%$ \\
\hline
\end{tabular}

Table 5. Incidence of Placenta Pervia.

\begin{tabular}{lll}
\hline TOTAL No. OF DELIVERIES & TOTAL No. OF PLACENTA PREVIA & PERCENTAGE OF PLACENTA PERVIA \\
\hline 5381 & 325 & 6.03 \\
\hline
\end{tabular}




\section{Discussion}

This is observational prospective study to find out the incidence and identifying the risk factors for placenta previa. These risk factors are important in the emergency situation which can aid in careful preoperative preparation and in counseling of women with placenta previa regarding morbidity and mortality.

Placenta previa can have serious adverse consequences for both mother and baby, including an increased risk of maternal and neonatal mortality [13-15], fetal growth restriction and preterm delivery [16], antenatal and intrapartum hemorrhage [17-19], and women may require a blood transfusion [20], or even an emergency hysterectomy. It is a relatively uncommon condition, with an overall incidence in England of 6.3 per 1000 births [21], but incidence rates are higher among women with advanced maternal age, multiple gestation, high parity, or who smoke or use illegal drugs [7]. The risk of placenta previa is also reported to be higher among women with previous uterine surgery, including cesarean section [22].

Cesarean sections constituted $25 \%$ of National Health Service (NHS) deliveries during 2010, and the rates have been rising for both primary and emergency CS 9 [21]. The risk of placenta previa in a pregnancy after a CS delivery has been reported to be between 1.5 and 6 times higher than after a vaginal delivery. A meta-analysis of studies published before 2000 of previous CS as a risk factor for placenta previa found an overall odds ratio of 2.7 [7].

Epidemiologic studies have identified several potential etiologic factors known to be associated with placenta previa and placental accrete system. The known risk factors for placenta previa include, Previous caesarean section, Placenta previa, Advanced maternal age, Multiparity, Previous myomectomy, Uterine curettage and Asherman syndrome, submucous lelomyomas, Thermal ablation, Uterine artery embolization, Prior pelvic irradiation, first caesarean sectionelective, IVF pregnancy, Previous trophoblastic disease, Uterine anomalies, Smoking. [23-26].

Many studies have proved the association of placenta previa with obstetrical risk factors including smoking, cocaine use during pregnancy and male fetuses [7, 27].

The independent risk factor for placenta praevia is a previous delivery by caesarean section. The risk increases with the number of caesarean sections performed. The incidence is $2 \%$ after one previous caesarean section, $4.1 \%$ after two and $22 \%$ after three [28]. Similarly dilation and curettage, evacuation of uterus and myomectomy are associated with placenta praevia. Placenta praevia is more common in older and multiparous women $[11,12,29]$. The reason is not clear but it may be associated with the ageing of vasculature of the uterus. This causes placental hypertrophy and enlargement which increases the likelihood of the placenta encroaching on lower segment [11].

This was observational prospective study in which we found incidence and risk factors of placenta previa. In this study we found Risk factors for placenta previa include pregnancy at late age, age $>35$ is 94 out $\mathrm{f} 325$ with percentage of $28.92 \%$, maternal smoking is 67 out of 325 with $20.61 \%$, multiparity is $44 \%$, and scarred uterus are the major risk factor for placenta previa which is 196 out of 325 with $60.30 \%$ and previous evacuation and curettage is 79 out of 325 with percentage of $24.32 \%$.

Placenta previa is an obstetric complication that occurs in the second third trimester of pregnancy. It may causes serious morbidity and mortality to the mother. Incidence of placenta previa and morbidly adherent placenta is on rise.

This is observational prospective study to find out incidence and risk factors of placenta previa. In this study we find Risk factors for placenta previa include pregnancy at late age, age $>35$ is 94 out of 325 with percentage of $28.92 \%$, maternal smoking is 67 out of 325 with $20.61 \%$, multiparity is $44 \%$, and scarred uterus are the major risk factor for placenta previa which is 196 out of 325 with $60.30 \%$ and previous evacuation and curettage is 79 out of 325 with percentage of $24.32 \%$.

\section{Conclusion}

It can be concluded that in our study pregnant women with previous cesarean section had a significant relationship with placenta previa. The effect of increase in age and high parity and smoking are also important factors for placenta previa. Which turn the pregnancy to high risk and results in high fetomaternal morbidity and mortality. Antenatal identification of these risk factors and conformation of placenta previa on Doppler ultrasound and involvement of Senior Obstetricician, Senior Pediatrician and Senior Anesthetist and associated team can minimize the fetomaternal morbidity and mortality. We can formulate the line of management for theses high risk pregnancies for better fetomaternal outcomes. Some risk factors are preventable like smoking, reducing cesarean section rates by careful fetomaternal monitoring. The role of proper information, education, and communication among all categories of health care providers should be a emphasized.

\section{Conflict of Interest}

The author declares no conflict of interest.

\section{Acknowledgements}

Author is grateful to all women participating in the study.

\section{References}

[1] Oyelese Y, Sumalian JC. Placenta previa, Placenta accrete and Vasa Previa. Obstet Gynecol 2006; 107: 927-41.

[2] L. Latif, U. J. Iqbal, and M. U. Aftab, "Associated risk Factors of placenta Previa a matched case control study,"Pakistan Journal of Medical and Health Science, Vol. 9, nou, pp. 13441346,2015 
[3] J. A. Cresswel 1, C. Ronnsmans, C. Calvert, and V. Fillipi”, Prevelance of placenta previa by world region: a systematic review and mata analysis. Tropical medicine and international Health, vol. 18, No. 6, PP. 712 724, 2013 view at publisher view at Google scholar. view at scopus.

[4] Obstetric hemorrhage is a leading cause of fetometernal morbidity and mortality.

[5] ACOG. Placenta accrete, Committee Opinion 2012; 529: reaffirmed 2015.

[6] Wu. S, Koch erinsky M, Hibbard JU. Abonormal Placentation: twenty-year nalysis. Am J Obstet Gynecol 2005; 192: 1445861 .

[7] Faiz AS. Ananth CV. Etiology and risk for placenta previa and overview and meta analysis of observational studies. $\mathrm{J}$ Matern Fetal Neonatal Med 2003; 13: 175-90.

[8] Jaunioun E, Collins S, Burton GJ. Placenta accrete spectrum pathophysiology \& evidence based anatomy for prenatal ultrasound imaging. Am J Obstet Gynecol 2017; 17: 3073130737.

[9] Nirma ala $\mathrm{CH}$, Mounisha NV, Placenta previa a study on maternal perinatal outcome ISOR Journal of Dental and medical science (IOSR-JDMS). 2017; 04 (7): 4-7.

[10] Meenakshi Devarmani, Patil Sanjana, Tallur. placenta previa: maternal and foetal outcome. J Evol Med Dent Sci 2016; 5 (40): 2477-80.

[11] Getahun D, Oyelss Y, Salihu HM, Anantha CV. Previous cesarean section delivery and risk of placenta previa and placenta abruption. Obstet Gynecol. 2006. Apr; 107 (4): 771778 .

[12] Odibo AO, Chahilla AG, Stamilio DM, Stevens EJ, Peipert JF, Macones GA. Predicting placental abruption and placenta previa in women ith pevious cesarean delivery Am J Perinatal. 20076 May; 24 (5): 299-305.

[13] Shreyasi S, Chanchal S, Sohani V, et al. Prenatal diagnosis \&management of morbidly adherent placenta. J Clin Diagn Res. 2017; 11: 1-2.

[14] Chaudhari HK, Shah PK, D'Souza N. Morbidly adherent placenta: its management \& maternal \& perinatal outcome. J Obstet Gynecol India 2017; 67: 42-47.

[15] Tikkanen M, Stefanovic V, Paavonen J. Placenta previa percreta left in situ-management by delayed hysterectomy: a case report. Journal of Medical Case Reports 2011: 5: 418421.

[16] Ananth CV, Demissie K, Smulian JC, Vintzileos AM.
Relationship among placenta previa, fetal growth restriction, and preterm delivery: A population based study. Obstet Gynecol. 2001; 98 (2): 299-306. doi: 10.1016/S00297844(01)01413-2.

[17] Brace V, Kernaghan D, Penney G. Learning from adverse clinical outcomes: major obstetric haemorrhage in Scotland, 2003-05. BJOG. 2007; 114 (11): 1388-1396. doi: 10.1111/j.1471-0528.2007.01533.x.

[18] Crane JMG, Van den Hof MC, Dodds L, Armson BA, Liston R. Maternal complications with placenta previa. Am J Perinatol. 2000; 17 (2): 101-105. doi: 10.1055/s-2000-9269.

[19] Bhide A, Prefumo F, Moore J, Hollis B, Thilaganathan B. Placental edge to internal os distance in the late third trimester and mode of delivery in placenta praevia. BJOG. 2003; 110 (9): 860-864. doi: 10.1111/j.1471-0528.2003.02491.x.

[20] Lydon-Rochelle M, Holt VL, Easterling TR, Martin DP. Firstbirth cesarean and placental abruption or previa at second birth. Obstet Gynecol. 2001; 97 (5): 765-769. doi: 10.1016/S0029-7844(01)01121-8.

[21] HESOnline. 2011. http: //www.hesonline.nhs.uk/.

[22] Ananth CV, Smulian JC, Vintzileos AM. The association of placenta previa with history of cesarean delivery and abortion: A metaanalysis. Am J Obstet Gynecol. 1997; 177 (5): 10711078. doi: 10.1016/S0002-9378(97)70017-6.

[23] Thia EW, Tan LK, Devendra K, et al. Lessons learnt from to women with morbidly adherent placentas and a reviews of literature. Ann Acad Med Singapore 2007; 36; 298-303.

[24] Kamara M, Kamara JJ, Henderson DA, et al. The risk of placenta accreta following primary elective caeseran delivery: a case control study. BJOG 2013; 120; 879-886.

[25] Fitzpatrick KE, Sellers S, Spark P, et al. The management and outcomes of placenta accrete, increta and percreta in the UK: a population based descriptive study. BTOG 2014; 121: 62-71.

[26] Society for Maternal fetal medicine. Clinical opinion. Placenta accreta AJOG 2010; 116: 431-439.

[27] Loto, Onile TG. Placenta previa at the obafemi A Wolow University teaching Hospitals Complex, $11 \mathrm{e}-1 \mathrm{fe}$. A ten years analysis. Niger J Clin Pract. 2008 Jun; 11 (2): 130-3.

[28] Lala ABH, Rutherford JM. Massive or recurrent ante partum haemorrhage. Current Obstetrics and Gynaecology. 2002; 12: 226-230.

[29] Eniola AO, Bako AU, Selo-Ojeme DO. Risk factors for placenta praevia in southern Nigeria. East Afr Med J. 2002; 79: 535-538. 